AÜIFD Cilt XLIV (2003) Sayt 2 s.325-335

\title{
Din Eğitiminde Bilimsel Araştırma
}

\section{Walter Houston CLARK / Çev.: Nurullah ALTAŞ}

Dr., Ankara Üniversitesi İlahiyat Fakültesi

e-mail: altas@divinity.ankara.edu.tr

Araştırma, ister din eğitimi alanında isterse diğer alanlarda olsun, birçok şekil almaktadır. Bununla birlikte, tarihsel, teolojik veya kutsal kitaplar konusu gibi daha genel çalışmalarla ilgilenmek yerine, bu bölüm, temel olarak başlıca sosyal psikolojik türden olmak üzere ampirik çalışmalar

- Makale, editörlüğünü Marwin J. Taylor'un editörlüğünü yaptığı ve 1960 yılında New York'ta yayınlanan "Religious Education-A Comprehensive Survey" isimli derleme içinde 78-86. sayfalar arasında yer almaktadır. Çalışmanın tarihi eski olmakla birlikte Hristiyan din eğitiminin bilimselleştirilmesi çabalarının kısa bir özetini gözler önüne sermekte, bu çabalar karşısındaki teolojik engeller ve engellemelerden bahsetmektedir. Bu açıdan, Türkiye'de din cğitiminin bilimselleştirilmesi çabalarında yol gösterici olacağını düşünmekteyim. (N.A.) 
üzerinde duracaktır. Diğer alanlarla karşılaştırıldığında bu alanda çalışma azlığı olmasına rağmen, hâlầ çeşitli niteliklerde olmak üzere yeterli çalışma vardır ve bu nedenle de dikkatli bir seçme yapılmalıdır'. Araştırmanın bilgiye nasıl katkıda bulunabileceğini ve din eğitimini nasıl etkileyeceğini somut örneklerle ele almaya çalışacağız.

\section{Din Eğitiminde Araş̧ırmanın Tarihçesi}

Konunun önemi dikkate alındığında, din eğitimi alanında bu kadar az yeterli araştırma girişiminin olmasının nedeni bir yandan, kısmen de olsa sosyal bilimcilerin, dinin bu tür yöntemlerin uygulanması için çok karmaşık bir alan olduğu şeklindeki dıygularının bir ifadesi olurken diğer yandan ise, birçok dindar kilise insanının sosyal bilimcilerin, kutsal mıntıkaları olarak tanımladıkları alanlarına karışmalarına itiraz etmeleridir. Bu tür etkiler, bir taraftan sosyal bilimcileri önemli sosyal ve psikolojik görüler elde etmelerinden mahrum etmiş; diğer taraftan kiliseler de bazı alanlardaki başarılı çalışmaların din eğitimi programlarına sağlayabileceği katkıyı kazandırmada başarısız olmuşlardır.

Sonuç olarak kişi bu alanın tarihini araştırdığında göze çarpan sadece iki ana çabaya rastlayabilir. Birincisi, Din Eğitimi Birliğgi tarafından önerilen ve Columbia Üniversitesi'nin sponsoru olduğu ve Mark May ve Hugh Hartshore tarafından yönetilen Karakter Eğitimi Araştırması'dır. Bu araştırma 1920'lerde yürütülmüştür ama hâlâ alanda etkisi vardır. Araştırma; dürüstlük, özdenetim ve işbirliği yapma gibi genellikle kiliseler tarafından öğretilmesi gereken kişilik özellikleri hakkında, kontrol altındaki gerçek yaşam şartlarında ${ }^{2}$ tasarlanmış nitelikli testler kullanılarak yapılmıştır. Araştırmanın ana bulgusu hakkında, yani kişilik özelliklerinin tutarlı olması ve genellenebilirliliği ile ilgili pek az bulgu olduğu noktasında geniş çapta eleştirilere hedef olmuştur ${ }^{2}$. Dahası, bu (karakterler), sadece bazı özel durumlarda ortaya çıkar. Bundan hareketle, May ve Hartshorne, para konularında ve atletizm sahasında çok dürüst olan bir çocuğun sınıfta sınav

1 Ulusal Kiliseler Birliği Hristiyan Eğitini Bölümü her yıl din eğitimi alanında yapılan bilimsel çalışmaları listeleyen çalışmalar yayınlar. Bunlar genellikle New York 545 West 111 th St.'de bulunan Din Eğitimi Kurumunun yayınladığ "Din Eğitimi" isimli dergide yayınlanan çalışmalardır. Listedeki diğer çalışmalar ise Psikoloji, Sosyoloji ve Eğitim abstraklarında yer alan dergilırde yer almaktadır. "Din Eğitimi Kurumu" bu alanda yapılacak bilimsel çalışmalara rehberlik etmck ve destck olma fonksiyonu olan bir komite oluşturmuş̧ur. Son zamanlards Karakter Eğitimi Projesiyle ortaklık içinde Kurum, bu araştırma için doküman toplanmasına yardımcı olmuş ve bu çalışmayı "Din Ĕ̆itimi" dergisinin 1959 Mayıs-Hazıran sayısında yayınlamışır. Kurum, alanda ihtiyaç duyulan ve yürütülmesi mümkün olan konulardaki araştırmalara destek olmaya devam ettikçc de bu raporların yayınlanması devam edccektir.

2 H. Hartshorne ve M. May, Studies in Deceit; Studies in Service and Self Control; H Hartshorne, M. May ve F. K. Shuttleworth. Sudies in the Organization of Character

"Örneğin Gordon W. Allpon, Personality, 9 
sırasında böyle olmayabileceğini bulmuştur. Çıkan sonuçlarla ilgili sorulara rağmen, Hartshorne ve May'in araştırması, en azından iki önemli işlevi yerine getirmiştir. Birincisi, zor bir alan olan karakter alanında iyi bir model çalışma olma özelliğine sahiptir ve böylece bu alanda daha küçük çaplı ama önemli çalışmaları motive etmiştir. İkincisi, din eğitimcilerinin dikkatlerini karakterin sadece söze dayalı eğitimin karşıtı olan bilimsel (emprik) eğitime çekmişlerdir. Bu, din eğitiminde bizim de hâlen yapmakta olduğumuz gibi etkinliklere, katılım ve kişisel ilişkilere olan vurgunun artması anlamına gelir.

Bu alandaki ikinci önemli araştırma çabası Ernest M. Ligon tarafından yönetilen ve New York Schenectady'deki Union Kolej'de yapılan Karakter Araştırma Projesi'dir. Bu, bir kaç yıldan beri devam eden bir çalışmadır ve hâlâ Lilly Endowment tarafından finanse edilerek sürmektedir. Karakter Eğitim Araştırması'nda olduğu gibi, bu araştırma da büyük oranda, Hristiyan kişilik özelliklerini çıkarsamak için Hristiyan İncillerinin bir çalışmasını yapan Ligon'un raporundakiler gibi, kişilik özellikleri ile ilgilenmektedir ${ }^{4}$. Karakter Araştırma Projesi'nin bulguları Ligon tarafından özetlenmiş ve 1956'da basılmıştır'. Araştırmalar şimdiye kadar devam ettiğinden, C.R.P. sürekli yeni alanlar açmakta; öyle ki araştırmasını sürekli yenilemek isteyen birinin son kullanılan referansları elde etmek için projeye yazması tavsiye edilmektedir ${ }^{6}$.

Karakter Araştırma Projesi birçok araştırmaları içerisinde, ana bulgularını ev dinamikleri, bireysel farklılıklar ve gençlik alanları içinde bulunduğunu düşünmektedir. Birinci isimlendirilen alanda üzcrinde çalışılan temel soru şudur: "Din eğitimi için en uygun olan evlerin özellikleri nelerdir?" Burada içinde en yüksek potansiyellerin bulunduğu evlerin özelliklerini belirlemek için faktör analizi ile küme analizi metotları kullanılmıştır. Bu bilgiyle, aileler, karakter gelişimi için evlerinde uygun bir ortamı geliştirmek amacıyla uygun faktörleri güçlendirebilmiş ve uygun olmayanları da zayıf bırakabilmişlerdir.

Bireysel farklılıklar alanında çalışılan temel soru şudur: Çocukluk süresi içinde yer alan her yaş düzeyindeki yetişme imkânları ve biricik kişiliği dikkate alınarak bir çocuğun ruhsal potansiyeli tam olarak nasıl gerçeğe dönüştürülebilir?

Burada güven ailelerin verdikleri cevaplara ve gelişimle ilgili çalışmalara dayandırılır. Bu çalışmalar, olgunluk kavramının entegrasyonel bir süreç olduğunu doğrulamıştır. Davranışlardaki yüksek puanlar ile diğer karakteristik özellikleri ilintili bulunmuş buna karşılık az puanlar ilintili bulunmamıştır. gelişimle ilgili çalışmalar sonraki yaş düzeylerinde ortaya çıkacak olgunluğun öndeyicilerini sağlamıştır. Ana okulu çocukları arasında

\footnotetext{
4 The Psychology of Christian Personality

5 Dimensions of Character

6 Bu özet bulgular William Koppe den alınmıştır. Union College. Schenectady. New York
} 
büyümeye yönelik arzu ile üçüncü derecede okuyan öğrencilerden ebeveynlerinin otoritelerini sorgulamalar buna örnektir. Bireysel farklılıklar üzerindeki çalışmalar, genellikle rol oynama yöntemi yoluyla, çok çeşitli özelliklere sahip çocuklara uygulanabilir müfredatlar oluşturma yöntemleri de geliştirmişlerdir.

Gençlik alanında temel soru şudur: "Gençlere, kendi dinsel gelişmelerinin sorumluluklarını üstlenmeleri için nasıl meydan okunmalıdır?" Farklı yöntemler yoluyla gençlerdeki tavırla ilgili faktörlerin eşit öneme sahip oldukları düşünülebilecek diğer faktörlerden daha önceliğe sahip oldukları öğrenilmiştir. Zeka, öğretmen etkinliği, kilise mezhepleri, yaşanılan kasabanın dinsel eğitimı ve: gelişmeyle ilgisiz olduğu anlaşılmıştır. sürece etkin katılımın, gençliğı̀n amaç belirlemediği vakalar karşılaş̧ırıldığında, gelişimi kolaylaştırdığı tespit edilmiştir.

Önceki çalışmalar çalışılan alanların küçük bir örneklem alımı ve Karakter Araştırma Projesi'nde (CRP) ulaşılan sonuçlardan ibarettir.

\section{Din Eğitiminde Araştırma Yöntemleri}

Burada, bazı gözlemler yapmak ve yer sinırlamalarının bunu sadece isimleri vererek yapmamıza olanak tanımasına rağmen din eğitimi alanında araştırma yapmanın başlıca yöntemlerine dikkat çekmek istiyoruz. Din, kendisi, sosyal bilimlerin uzanabileceklerinin çok ötesinde değerler ve konular içerir. Yine de bu, din eğitimcisini ne kadar güç olursa olsun ciddî çalışmalar yoluyla cevap verilebilecek sorulara net cevaplar arama görevinden azade kılmaz. Örneğin, pazar günü yapılan eğitimin kişiliği (karakteri) önemli ölçüde etkilediği hep varsayılmıştır. Hartshore ve May bunun bu şekilde olup olmadığını sorduklarında ve sonuçları incelediklerinde bunu destekleyecek çok az kanıt bulmuşlardır. Pazar okuluna devam etmenin ${ }_{1}$ özdenetim ve dürüstlük gibi özellikler üstünde pek etkisi olmadığı görülmektedir. Din eğitimi programlarının iyileştirilmesinin umdelerinden en azından birinin kilise okullarının pembe yanılsamalarını silip süpürmesine yardım edecek ve onların programlarını daha verimli yönlere yöneltecek sağlam tir eğitim programıdır.

Anket ve mülakat en sik kullanılan metotlardandır ki her ikisi de, ister standart isterse açık uçlu colsun, deneyimsiz kişiler tarafından kullanılması söz konusu olduğunda oluşturulması aldatıcı derecede kolaydır. Dinsel eğilimleri ve koşulları ölçmek için rating skalaları kullanılırken May ve Hartshorne tarafından kullianılanlar gibi tam olarak oluşturulmuş testler de kişilik ölçümü için dahả gę̧erli fakat cevaplama açısından daha güç testler arasındadır. Özellikle de denetimlerinin sağlanmasının güç olmasından dolayı deneylerin din alanındaki kullanımı, özellikle güç olmasına rağmen bir test veya diğer aletler dencyle bağlantılı olarak kullanılabilir. Bu yöntemlerin yanı sıra, araşırmacıların, istatistik bilimi konusunda da biraz bilgi sahibi olması gerekmektedir. Gelişim yaklaşımı, projektif teknikler, klinik yöntem ve bunlara ilave bir dizi yöntemi içeren sosyolojik araştırma 
diğer yöntemleri oluşturur. Kişiliğgin karmaşık yönlerini araştırmak için son zamanlarda geliştirilmiş istatistiksel bir araç da faktör analizidir.

Bu çok karmaşık listeden bile açıkça anlaşılmaktadır ki, araştırmayla ilgilenen din eğitimcisi iyi bir teknik geçmişe ve eğitime gereksinim duymaktadır.

\section{Seçkin Bir Grup Olarak Dinsel Liderlik}

Bu alanda, az önce bahsettiğimiz Karakter Eğitimi Araştırma ve Karakter Araştırma Projelerine ek olarak bahse değer kısa ebatlı birkaç çalışma daha vardır. Hem Karakter Eğitimi Araştırma hem de Karakter Araştırma Projesi kendilerini tamamen din eğitiminin de esasını teşkil eden konulara odaklamışlardır. Bundan sonraki aşamada ilgileneceğimiz çalışmalar ya geniş boyutlu alan araştırmaları (surveys) -ki bir bölümü din eğitimi ve sonuçlarıyla ilgilidir- içerirler ya da tamamen bu alana yoğunlaşmıştır. Fakat boyutları çok daha sınırlıdır. Bunların seçilme nedeni sadece onların bu alanla ilgili araştırmalar olmalarından değil ayrıca (bu türden her iyi araştırmalarda olacağı gibi) bulgularının pratik alanlarda önemli sonuçları olduğu içindir.

Havighurst ve Taba, Adoloscent Character and Personality (Ergen Karakteri ve Kişilik) adlı kitaplarında birkaç yüz ergen üzerinde gerçekleştirdikleri anketlerle, skala teknikleriyle, vak'a çalışmasıyla ve diğer uygun yöntemlerle yoğun bir çalışma yaptıklarını belirtmektedirler. Bunun sonucu olarak çalışma evrenlerini oluşturan grubu betimleyen beş ahlâksal grup (çeşit) tanımlamışlardır. Bunları şöyle isimlendirmişlerdir: Uyumlu, kendini yönetebilen, itaatkâr, uyum göstermeyen ve başkaldırıcı. Bunlardan "kendini yönetebilen" başat biçimde yaratıcı ve arzu edilir gözükmektedir. Bu gruptakileri içlerinde olumlu standartlara sahip olan ve kendileri ile ilgili ahlâkî seçimleri yaparken grubun yaygın standartları tarafından yönlendirilmeyen ergeneler oluşturur. Dahası, bunların lider oldukları belirlenmiştir ve örnek davranışları diğerleri için yararlı örnek teşkil etme eğilimindedir. Kuşkusuz bu tip gençler din eğitimi için büyük öneme sahiptirler. Ama, diğer yandan, tüm grup içerisinde sayıları oldukça azdır.

Bir kişi araştırmanın zaten bilinen şeyleri yansıtıp yansıtmadığını sorabilir. Yani liderlerin azınlık olduğu şeklindeki saptamanın zaten bilinen bir şey olduğunu ileri sürebilir. Araştırma sadece grubu betimleyip onunla ilgili vaka örneklerini sunmamış, aynı zamanda bu beş grubun yaygınlığı ile ilgili sayısal tahminler ileri sürmüştür. Araştırma, din eğitiminin kendini yöneten bu gençler grubunu yeterince değerlendirip değerlendirmediği konusunu gündeme getirir. Demokratik sürece olan düşkünlü̆ğü içerisinde din eğitimi belki de demokrasinin herkese fırsat verme şeklindeki görevini yanlı̧̧ kavramış olabilir. Bu sadece çoğunluğun gelişmesi anlamına gelmemeli; aynı zamanda, kendi içlerindeki, herkese katkı yapabilecek yeteneklerini artırma kapasiteleri olanlar için fırsatların artırılması anlamına gelmelidir. Ruhsal ve ahlâksal işlev düşünüldüğünde aynı sonuçlara 
ulaşmamak için sebep yoktur. Bu belki de başka bir araştırmanın konusu yapılabilir. Genel olarak bu fikirler, Murray Gross'un The Religous Beliefs of Youth (Gençliğgin Dinsel İnançları) adlı kitabında yer alan büyük bir çoğunluğun yalnız kaldığında dinsel değil materyalist ve ben merkezci düşündüğü bulgusu ile desteklenmektedir. Sadece pek azı dinsel ve ilgili problemlerle üzerinde düşünür.

Bu tür bulgular hem bir tür ahlâkî elit' in bulunduğunu gösterir ve hem de dindeki eğitim metodunun az yoğunlukta "demokratik" olmayıp geçmişte aristokratik olarak çok tenkit edilenle aynı çizgide olup olmaması sorusunu gündeme getirir. Aslında bizim önerimiz kilisenin, demokrasi-aristokrasi karşıtlığı konusuyla din eğitimini neyin etkili yaptığı konusu kadar ilgilenmemesi doğrultusundadır. Havighurst ve Taba'nın ulaştığı sonuçlara göre iyi planlanmış araştırma kendini yöneten insanları daha etkili kullanmak için kilise okullarına önemli şekilde yön sağlayabilir. Aynı çalışmanın yukarıdakiy|le alakalı ve diğer araştırmacıların gözlemlerini doğrulayıcı diğer bulgusu da bütün din adamlarını düşündürtecek niteliktedir. Üzerinde çalışma yapılan çocukların çoğunun kilisenin öğretilerine nazaran sımıflardaki davranı̧̧lardan daha çok etkilendiği şeklindedir. Onların genel güvenilirliğinin ve yardımlaşmalarının değeri onların kiliseye bağlı olup olmamalarıyla değil sınıftaki statüleriyle daha iyi ölçülür. Hartshorne ve May'in de aynı ya da çok benzer sonuçlara ulaştığından bahsetmiştik. Bu ortalama bir gencin kendi sosyal grubundaki arkadaşları gibi davranma isteği onun kilisenin öğretilerine uyma isteğinden daha önemli olduğunu gösterir. Sosyal sınıfın ahlâkî değerleri kilise öğretisiyle aynı noktada birleştiğinde davranış da buna karşılık verme eğilimindedir; kiliseden ayrılmış iki kilise üyesi artık kilisenin emirlerine uyma ihtimali kalmadığında kilise üyesi olmayanlar da onlara karşılık verir.

Hollignshead'ın yazdığı karşılaştırmalı bir çalışma olan Elmstown'ın gençleri'nde Havighurst ve Taba'nınkiyle ilgili açıklayıcı bir örnek bulunmaktadır. Elms Kasabası'nda bir Metodist kiliseye ait biri üst birisi de alt sınıftan kızlar tarafından desteklenen genç kadınlar için iki gençlik örgütü bulunmaktaydı. Bu düzenlemede yer aldığı ima edilen, Hristiyanlık ilkelerinin çok açık inkarına karşı çok hassas olan yeni bir papaz bu iki grubu birleşmeye ikna etmiştir. Yeni örgüt birkaç ay içinde katılım azlığı nedeniyle kapanmak durumunda kalmış ve herhangi bir aktivitenin yeniden canlandırılması için geleneksel grupların eski şekillerini almaları zorunlu olmuştur.

Genel bulgulara açık bir istisna bulunduğunda bile araştırmacılar, farkı tamamen dinsel mülahazaların oluşturduğunu açığa kavuşturmamışlardır. Norveç Luther Kilisesi ile bağlantılı bir grup genç övgüye değer davranış konusunda sosyal sınıf statülerinden daha fazla şöhrete sahip olmuşlardır. Buna büyük oranda bölgesel papazın sıkı kontrolünün ve kilise grubunun yüksek grup içi ahlâklılığının sebep olduğu gözükmektedir. Sosyal aktivitelerin grup üyeleri arısındaki ilişkilere hasredildiği ve bu tahsisin de 
kilisenin kendisi tarafından düzenlenen aktiviteler tarafından motive edildiği eğilimi bulunmaktadır. Kilisenin tasvip ettiği davranışlardan sapışlar, dinî olmaktan ziyade sosyal nitelikteki sınırlamalarla cezalandırılmıştır. Sapkın olanlar, grup tarafından dışlanmışlardır. Çünkü ortalama bir kilise üyesi sosyal ilişkiler konusunda kiliseye o kadar bağımlı olmuştur ki onun bu değerler dizininden ayrılması için aşırı uçlardan biri olan ya istisnai güçlü bir kafa yapısına sahip olması ya da çözüm konusunda son derece zayıf olması gerekir.

$\mathrm{Bu}$, bu kilisenin cemaate sunduğu hizmetin değerini, ki bu çok büyüktür, sorgulamak değildir. Bu sadece kullanılan motivasyonların büyük oranda zarurî olarak dinî olmayıp daha ziyade sosyal etkileşim ihtiyacından ve grup tarafından reddedilme korkusundan kaynaklanmakta olduğuna işaret etmektir. Praire City'deki Norveçli Lutherler moral davranışı desteklemek konusunda grup motivasyonunu kullanmada başarılıydılar. Diğer kiliselerde gençler kendilerini ciddî bir şekilde daha geniş sosyal sınıfla özdeşleştirmişlerdir. Araştırma bu hâliyle dinî motivasyonun oynadı̆̆ı role açıkça işaret etmez. Belki de bu orada vardır ve kişi de özelikle bazı bireyler için bunun böyle olduğu konusunda şüphelenmektedir. Fakat burada daha fazla araştırma için bir alan bulunmaktadır ve bu araştırmaların hem din eğitimcisi ve hem de din sosyologu için öğretici olacağı gözükmektedir. Aksi takdirde, bizim sahip olduğumuz araştırma, kredisini dinin sıkça tek başına elinde bulundurduğu arzu edilir davranışların sosyal etkileşimlere olan önemli borcuna işaret etmektedir. Eğer kilise kendi din eğitim programını iyileştirmek niyetinde ise dinî ve sosyal faktörler arasındaki etkileşiminin daha net anlaşılmasına bu alanda ihtiyaç bulunmaktadır.

\section{Harms'ın Çalışması}

Sonuçları bu alanı ilgilendiren bir diğer çalışma yansıtma metodunun kullanımını yansıtır. Harms'a ${ }^{7}$ ait bu çalışmada farklı yaşlardaki çocuklara Tanrının bir resminin çizilmesi ve onun anlamının açıklanması istenir ${ }^{8}$. Sonra sonuçların üzerinde çalışılır ve tasnifleri yapılır. Kısaca bu çalışmalar göstermiştir ki 6 yaşına kadar olan çocuklar fanteziyi çok kullanmışlardır; 612 yaş arasındakiler kendilerine ögretilenlerden esinlenerek daha realist düşünceler sergilemişlerdir. Ergenlikte ise bu düşünceler çok geleneksel düşüncelerden tutun da çok orijinal olanlara kadar olmak üzere çok farklılık göstermiştir. Orijinal olanların düşünceleri sürpriz bir şekilde açıkça çocukların ilişki hâlinde olmadığı ezoterik dinî düşüncelere benzerlik arz etmiş̧ir. Bu sonuncuları ergenler içerisinde orijinal ve yaratıcı dinî düşünce ihtimallerini ima ediyor. Kiliseler gençlerle yaptıkları çalışmalarında bu yaratıcılık için uygun şartları oluşturup oluşturmadıklarını kendilerine

\footnotetext{
" Ernest Harms, "The Development of Religious Experience in Children", American Journal of Sociology, L (1944), 112-122

* Bu çalışmanın bir özeti resimlerle birlikte Clark'ın Op.cit. Ch.5'te bulunmaktadır.
} 
sorabilirler. Gerçekten de bu pek çok kilisenin gençlik programlarının neden kalite yokluğu için bir ip ucu olabilir.

Ama belki de Harms'ın çalışmasının daha önemli boyutu genç çocuğun din eğitimiyle ilgilidir. Ëger Harms'ın bulguları sağlamsa ve dinî hizmet de çocuğun tabii yeteneğine dayandırılması gerekiyorsa fantezinin okul öncesi din eğitiminde kısmen yer alması gerektiği gözüknektedir. Bu durum çocuğun imgelemine hitap :den hikaye ve mitler lehine olmak üzere bu ilk dönemde mantık ve gerçek.liğe olan aşırı vurguyu sorgulayabilir. Bunun egzersizi bu dönemdeki çocuğa onun hiç bir zaman bilemeyeceği bir yoğunlukta belirli bir mutluluk sağlayabilir. Bu, dine karşı hayat boyu sürebilecek olan övgüye değer tavırlara yardımcı olacaktır. Diğer çok önemli bir mülahaza da bizlerin mitler yoluyla gerçekliği net olarak kelimelerle betimlenecek şeffaf olan bir duruma taşımış olmamızdır. Bu C.G. Jung'un ${ }^{9}$ argümanıdır ve Tevrat'ta bolca bulunan dinî harikalar ile ilgili hikayeler kilise-okul müfredatından çıkartıldığında rasyonel sarkacın hareket alanının genişleyip genişlemeyeceği sorgulanabilir. Çocuğun mitlerin gerçek önemini anlaması için yeterince büyiumesini beklemek, belki de onların sahip olduğu erdemin ayrılmasını beklemek olacaktır. Çocukların çok fazla büyümüş gözleri parlama, kalpleri de acele etme yetilerini kaybedebilir. Duygusal uyarımlar olmaksızın dinin derin dersleri kesinlikle öğrenilemez. Bu yüzdendir ki Harms'ın tavsiye taşıyan bulguları daha fazla araştırmalarla devam ettirilmelidir.

\section{Cinsel İliş̧i ve Din,Eğitimi}

Tüm Amerikan gençliği arasındaki en önemli potansiyel çatışma kaynağı cinsel dürtüdür. Bunun kilise aracılığı ile uyandırılan sıkı kısıtlamalardan dolayı özellikle kilise çevresinde önemli olduğunu sanıyoruz. Bunun etkileri farklı farklıdır; bir bakıyorsun genci güçlendiriyor, bir bakıyorsun ona eziyet ediyor, bir bakıyorsun onu entegre edip güçlendiriyor, bir bakıyorsun bir çocuk olarak kalmaya devam edecek kadar utanma ve şüpheyle ona häkim oluyor. Bu sorunla esnek olmayan emirler yoluyla ilgilenmek yerine, gençleriṇin ahlâkî ve ruhsal yetişmelerine katılmayı arzulayan kilise tabii potansiyelin en yüksek derecede yetişmesine izin verecek olan izin verme ile katı bir tutum arasında bir yol belirlemclidir. Yapılan bir çalışma ${ }^{10}$ göstermiştir ki Oxford grubuna karşı lehte veya aleyhte bir tavır alışın, bireyin cinsel ilişkiyle ilintili lehte veya aleyhte deneyimleriyle bağlantıli oldluğu tespit edilmiştir.

Genel olarak, sorunın tam boyutuyla ilgili, kiliselerin konuyla ilgilenmelerinde başarılı olup olmadıkları ile ilgili veya hangi yöntemlerin onu çözmede başarılr olup olmadıkları ile ilgili çok fazla bilgi bulunmamaktadır. Örneğin, bizler, dikkat etmemiz gerektiği konusunda

\footnotetext{
9 Modern Man in Search of a Soul ve The Undiscovered Self

11" Walter H. Clark, The Oxford Gioup: Its History and Significance
} 
emin olmakla beraber, liderlik kalitesinin ne derece önemli bir unsur olduğunu veya liderliğin uygulanış boyutunu bilemiyoruz.

Bildiğimiz şey, özellikle mastürbasyon sorununda olmak üzere, tasvip edilen cinsellik normlarından az bir kopuşun, gençlerin çoğunda stres yaratması ve aynı zamanda yoğun suçluluk duygularının yaygın olmasıdır. Kilise, bir genci onun uğraşısında yalnız olmadığı gerçeği ile tanıştırarak yoğun suçluluktan kurtarması konusunda borçlu olduğundan da eminiz. Bu yolla cemaat duygusu içerisinde onu restore etmek yoluyla (tıpkı İsa'nın kuyudaki bir kadınla yaptığı gibi) kilise genci cinsel ilişki düşünceleriyle meşgul olmaktan dolayısıyla da onu amacından uzaklaştıran şeylerden kurtarmış olur. Aynı zamanda bu yolla elde edilecek olan öz-saygı, onu (genci) yaptığı her şeyde çoğunluğu takip etme zorunlu teşvikinde kurtarması ve onun kendi doğru ahlâkî ve ruhsal benliğini takip etmesine izin vermesi gerekecektir.

Açıkça anlaşıldığı kadarıyla bu alanda araştırma yapmak güç olacak fakat öneminin belirginliği ise ortadadır.

\section{Krize Bağlı İhtida ve Din Eğitimi}

Krize bağlı ihtida, din bilginlerinin bazen nefretini bazen de ilgisini çekmiştir. Evangelistik ilerlemenin düşük sınıf unsurlarıyla meşhur olduğu düşünüldügüunde, bütün kalple kabul etme onlara hiç bir zaman oldukça saygın gelmemiştir. Yine ortalama orta ve üst sınıf din eğitimcileri ihtida'yı nasıl teşvik edeceklerini ve aynı zamanda bütünlük taşıyan sonuçlar konusunda emin kılmayı bilmiyorlar. Bundan dolayı pek çok eğitim teorisinde peyderpey bir gelişim varsayılmış ve son zamanlarda ani ihtida konusunda Hristiyan eğitimine katkı sağlayabilecek çok az araştırma bulunmaktadır.

İlk tarihsel çağlardan günümüze kadar kişilikte olan dramatik ve etkili değişiklikler bu olguya dikkati zorlamıştır. İhtida ile ilgili en son yoğun araştırma E. T. Clark tarafından yapılmış ve 1929 'da yayınlanmıştır' ${ }^{\prime \prime}$. Bu başlıca kolej öğrencileri üzerine yapılmış ve onların \% 7'sinden daha azı dramatik ani bir ihtida geçirdiklerini belirtmişlerdir. Bu rapordan ani ihtidanın şu veya bu şekilde din alanında çalışanlarda diğerlerine göre en azından altı kat sıklıkta vuku bulduğu saklanmıştır ${ }^{12}$.

Bu sonuç iki şeyi ima etmektedir: Birincisi, dinî olarak konuşmak gerekirse ihtida daha sürekli sonuçlar üretmektedir; ikincisi, ihtida çalışmalarına bunun kesin olup-olmadığını anlamak için daha fazla ihtiyaç vardır. Din alanında -özellikle de Hristiyanlık eğitimi alanında- çalışan personelin azlığı, ki eğer etkili biçimde çalışanların büyük oranını üreten ani

\footnotetext{
"The Psychology of Religious Awakening

12 Aynı zamanda benim Clark'ın rakamlarını yorumladığım The Psychology of Religion isimli çalışmama bakınız.
} 
ihtida ise, diğer bilgilere ek olarak bilinmelidir ki ihtidanın bütünsel sonuçlar ürettiği şartları belirleyebiliriz.

\section{Birleşik Presbiteryanlların Aile Araştırma Projesi}

Karakter Araştırma Projesi'nin denetimi altında devam etmekte olan biraz önce bahsettiğimiz çalışmaya ek olarak okuyucuların bilgilendirilmek isteyeceği araştırma alanında devam etmekte olan önemli bir gelişme daha vardır. Bu Amerika'daki Birleşik Presbiteryan Kilisesinin Hristiyan Eğitimi Heyetince finanse edilen aile din eğitimi ile ilgili kapsamlı bir araştırma projesidir $^{13}$. Hazırlık çalışmasından sonra aile ile ilgili görevleri konusunda papazlara anketler gönderilmiş ve yine anketler yoluyla bini aşkın aileyle mülakatlar yapılmıştır. Bu bilgilere psikologlarla, öğretmenlerle, halk sağ lı̆̆ı çalışanlarıyla ve aile eğitimi alanında çalışan diğer kişilerle yapılan mülakatlar da eklenmiştir. Bu veriler yeni bir tür aile eğitimi için program intimallerini test etmek amacıyla pilot deneylerde aksiyon araştırması (action research) yapmaya zemin hazırlayacaktır. Projenin tam bir raporunun 1960 veya 1961 'e kadar basilması umulmaktadır.

\section{Din ve Araştırma}

Bu bölüme bir dipnot niteliğinde olarak din eğitimi alanında çalışanlar için bazı yorumlar yaparak bu konuyu burada noktalamak istiyoruz. Araştırmacının felsefesi pozitivizm felsefesi olmuştur. Bu kısaca bir olgu ile onu ortaya çıkaran arasında, ortaya çıkaranın sözle ifade edilebilir ve genellikle de ölçülebilir olması koşuluyla, sıkı bir sebep ve etki bulunduğunu varsayar. Pozitivist, doğanın yasaları olduğuna ve bu nedenle de eğer gerekli bilgilere sahip isek tamamen kestirilebilir olduğuna vurgu yapar. Öyle ki özgür irade bir gerçek olnaktan ziyade bir yanılsamadır. Araştırma yapma amaçları açısından böylesi kabullenmelerin, özcllikle de içinde bulunduğumuz dönemde scsyal bilimler açısından kaçınılmaz olduğu açıkır.

Dinsel yanı ağır basan bir araştırmacı böylesi bir felsefeyi yaşamının çeşitli alanlarına taşımayı arzu etmeyebilir. Dahası o, bir insanın enerjinin önemli bir bölümünü harcadığı şey onun felsefesi ve dinî olur düsturunu düşündüğünde endişelenir. Pozitivist bir arayış, pek çoğuna göre de bir sosyal bilimci, dine bir tür alternatif oluşturur. Tam bilginin mükemmel bir öndeyiye ve dolayısıyla da mükemmel kontrole götürmesi, sosyal bilimcileri saatlerce süren ciddî ve sık.ıntılı çalışmaya sevk eden bir inançtır. İşte biz bu emeğe pek çok bilimsel gelişmeyi borçluyuz ve din de din eğitimi alanında onu daha fazla kullanmak için iyisini yapacaktır.

Aynı zamanda o, din eğitimcisinin böyle yaptığının bilincinde olarak kendi doğum hakkını böyle bir materyalistik karmaşıklığa satması tehlikesine karşı korumak isteyecektir. Son zamanlardaki iyileşme

\footnotetext{
${ }^{13}$ Bu proje hakkındaki bilģilendirmelerinden dolayı Aile Eğitim Araştırması Bölüm yöneticisi John Charles Wynn'e teşckkürler.
} 
belirtilerine ${ }^{14}$ rağmen sosyal bilim bütün akademik disiplinlerin en az din̂̂ olanı olarak devam etmektedir. Belki de bu noktadadır ki din kendisi kalarak ve nihaî olarak daha üretici bilime götürecek daha geniş bir insan kavramını telkin etmek suretiyle sosyal bilime hizmet edebilir. Hem sosyal bilimler hem de din, din eğitimi alanındaki araştırmaları genişleten yakın ilişkilerden kazanç sağlamaya çalışacaktır. Sonuca götüren bir etkileşim içerisinde dinî araştırmacı iç görülerinin ikili problemleri çözmeye katkıda bulunmasını arzu edecektir. Bu makale araştırmanın yardımcı olduğu ve olmaya devam edebileceği bazı yöntemleri önermeyi denemiştir.

\section{BIBLIYOGRAFYA}

Allport, Gordon W. Personality. New York: Henry Holt and Company, 1937

Becoming: Basic Consideration for a Psychology of Personality.New Haven: Yale University Pres, 1955

Clark. Emler T. The Psychology of Religious Awakening. New York: The Macmillan Company, 1929

Clark, Walter Houston. The Psychology of Religion. New York: The Macmillan Company, 1958

The Oxford Group: Its History and Significance. New York: Bookman Associates, 1951

Harms, Ernest. "The Development of Religious Experience in Children" American Journal of Sociology, L(1944), 112-22

Hartshorne, Hugh; May, Mark; and Maller. Julius B. Studies in Deceit. New York: The Macmillan Company, 1928 1929 Studies in Service and Self Control. New York: The Macmillan Company,

Hartshorne, Hugh; May, Mark; and Shuttleworth. F. K. Studies in the Organization of Character. New York: The Macmillan Company, 1930

Havighurst, Robert J. And Taba, H. Adolescent Character and Personality. New York: John Wilcy and Sons, Inc.. 1949

Hollingshead. A. B. Elmtown's Youth. New York: John Wiley and Sons, Inc.. 1949

Jung, Carl G. Modern Man in Search of a Soul. New York : Harcourt, Brace and Company, 1923 ,The Undiscovered Self. Boston, Little, Brown and Company, 1956

Ligon, Ernest M. Dimensions of Chiristian Personality. New York: The Macmillan Company, 1937.

Ross. Murray G. The Religious Beliefs of Youth. New York: Association Pres, 1950.

it Örneğin Gordon Allport'a bakınız: Becoming: Basic Consideration for a Psychology of Personality 